\title{
Journal of Chemistry and Applications
}

Review Article Open Access

Nanotechnological advances of Lipid film-based biosensors for the rapid detection of biological compounds and toxicants

\section{Georgia-Paraskevi Nikoleli}

\section{Hellenic Army Academy Department of Physical Sciences, Vari GR-16673, Attica, Greece}

*Corresponding Author: Georgia-Paraskevi Nikoleli, Hellenic Army Academy Department of Physical Sciences, Vari GR-16673, Attica, Greece, Email: dnikolel@chem.uoa.gr

Received Date: Nov 08, 2019 / Accepted Date: Nov 20, 2019 / Published Date: Nov 22, 2019

\begin{abstract}
The exploration of lipid membranes for the construction of nanobiosensors has recently provided the opportunity to construct devices to monitor a wide range of compounds of biological interest. Nanobiosensor miniaturization using nanotechnological tools has given novel ways to attach a wide range of "receptors" in the lipid membrane. The lipids used to construct a lipid film-based device are dipalmiloylphosphatidylcholine $\{$ DPPC $\}$ and in some cases dipalmitoylphosphatidic acid (DPPA) which is an anionic lipid and is used to increase the sensitivity of detection. Most common "receptors" used in lipid film biosensors are enzymes such as urease, cholesterol oxidase, urecase, etc, antibodies such as Ddimer antibody and artificial or natural receptors such as saxitoxin, cholera toxin, calyx [4] arene phospjoryl receptor, etc. This chapter reviews and investigates the construction of nanobiosensors based on lipid membranes that are used to monitor various toxicants. It also exploits examples of applications with an emphasis on novel devices, new nanobiosensing techniques and nanotechnology-based transduction schemes. The compounds that can be detected are insecticides, toxins, hormones, dioxins, etc. Keywords: Lipid membrane based nanosensors; Nanoyechology; Graphene and ZnO electrodes; Food toxicants; Environmental pollutants; Clinical analysis
\end{abstract}

Cite this article as: Georgia-Paraskevi Nikoleli. 2019. Nanocomposites and their employment as scavengers of water pollutants. J Chem Appl. 1: 32-40.

Copyright: This is an open-access article distributed under the terms of the Creative Commons Attribution License, which permits unrestricted use, distribution, and reproduction in any medium, provided the original author and source are credited. Copyright (C) 2019; Georgia-Paraskevi Nikoleli

\section{Introduction}

A chemical sensor is a device that transforms the chemical information of the concentration of a specific analyte into an analytically useful signal. Chemical sensors consist of two components: a chemical recognition element ("receptor") and a physicochemical transducer. The recognition system translates the chemical information (i.e., concentration of the analyte) into measurable physical signal. The physical transducer provides the signal from the output domain of the recognition element into an electrical, optical or piezoelectric, etc. domain. A biosensor is a self-contained integrated device which is capable of providing specific quantitative analytical information using a biological recognition element (e.g., enzymes, antibodies, natural or artificial receptors, cells, etc.), which is retained in direct spatial contact with a transduction element. Recent reports 
have appeared in the literature that describe the nanotechological advances in biosensors [1,2].

The early 1960's attempts to reconstitute lipid bilayers in vitro gradually established the socalled "lipid membrane technology". The number ofbiosensors that based on lipid membranes that were used to monitor food toxicants, environmental pollutants and compounds of clinical interest has increased during the last twenty years. During the last decade, a number of efforts to construct stabilized lipid film biosensors were successful; this has given the opportunity to prepare sensors to monitor food toxicants and environmental pollutants in real samples and in the field. The advantages of lipid film biosensors are plenty: these membranes are biocompatible, they have rapid response times, high sensitivity and selectivity and are small size. The new generation of stabilized lipid film nanobiosensors has the potentiality to prepare analytical devices with high selectivity, sensitivity and stability.

Lipid membrane technology reduces the complex membrane properties and processes to well-controlled and defined interactions between biological moieties, lipids and transducers (Figure 1 and 2). Although the very nature of biological membrane still remains elusive [3], it is easy to isolate specific membrane properties for drug permeability [4] or protein-lipid interaction studies [5] or even to control and manipulate nano-processes on the lipid bilayer by changing macro-parameters $(\mathrm{pH}$, temperature, ionic strength, lipid composition, etc.) [6]. Biological moieties (enzymes, antibodies, receptors, ligands, DNA, etc.) can be easily immobilized on the surface of lipid membranes [7] or embedded into the lipid organization [5] using thermodynamically driven self-assembly processes or more precise techniques, such as patterning [8] or surface printing [9]. The lipid micro-environment presents a compatible setting for biological species to retain their full functionality while experimented upon. Further, the physical state of the lipid membrane offers an intrinsic signal transduction and amplification mechanism, perfectly fitted for electrochemical sensing: when the biological moiety, attached on or embedded in the membrane, interacts with the target analyte, lipid-protein and lipid-lipid interactions are affected to a degree sufficient to disrupt the lipid organization [10]; this affects the flux of ions through the membrane and can be readily detected as current alterations. Figure 1 shows the function and composition of a biosensor based on lipid film technology, illustrating, also, the physicochemical mechanism for the electrochemical transduction and the most common screening strategies employed. A number of recent articles have appeared in the literature that mainly describe recent advances and applications of various platforms of lipid film-based biosensors [6,10-14].

\section{Methods for the preparation of stabilized biosensors based on lipid membranes}

During the last 10 years, the construction of stabilized lipid film-based biosensors that can not collapse due to an electrical or mechanical shock and are stabilized in air has been reported by Nikolelis group. Below we report the methods for the preparation of nanobiosensors that are based on lipid membranes with advantages such as fast response times, nanosize high selectivity and sensitivity and are stabilized in air. 


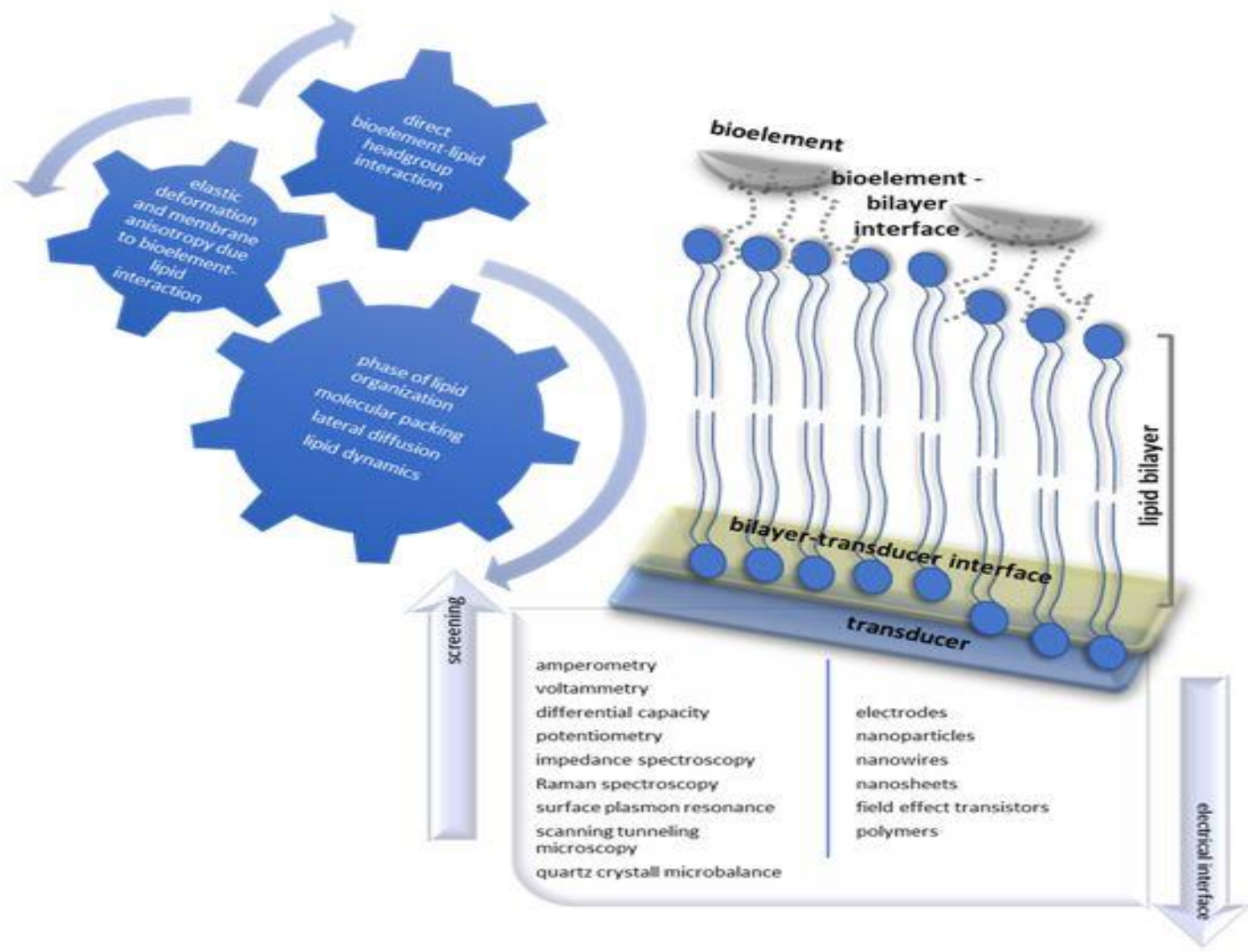

Figure 1: Simplified overview of the function and composition of a biosensor based on lipid film technology, illustrating, also, the physicochemical mechanism for the electrochemical transduction and the most common screening strategies [from ref. 11].

\section{Stabilized lipid films formed on a glass fiber filter}

The stabilized lipid films formed on a glass fiber filter have been used for the rapid detection of atrazine and for the selective and sensitive (nM detection limits) of simazine, areazine and propoazine. The preparation of stabilized in electrolyte lipid membranes was reported by Nikolelis group and these membranes were constructed on GF/F glass microfiber $(0.9 \mathrm{~cm}$ in diameter and $0.7 \mu \mathrm{m}$ nominal pore size) filters [16,17]. The lipid used were previously described. No receptor was used in these detections. A diagram of the experimental set-up is provided in Fig. 2. The stable in electrolyte solution lipid films were prepared as follows [16,17]: $10 \mu \mathrm{L}$ of a lipid solution in hexane was positioned at the electrolyte surface in the cylindrical cell and the level of the electrolyte was brought below the hole of the partition and then raised again within a few seconds. Once the lipid membranes were formed, the current was at the $\mathrm{pA}$ and the injection of gramicidin D shows that these membranes were bimolecular. 


\section{Nanotechnological advances of Lipid film-based biosensors for the rapid detection of biological compounds and toxicants}

DOI: https://doi.org/10.36811/jca.2019.110004

JCA: November-2019: Page No: 32-40

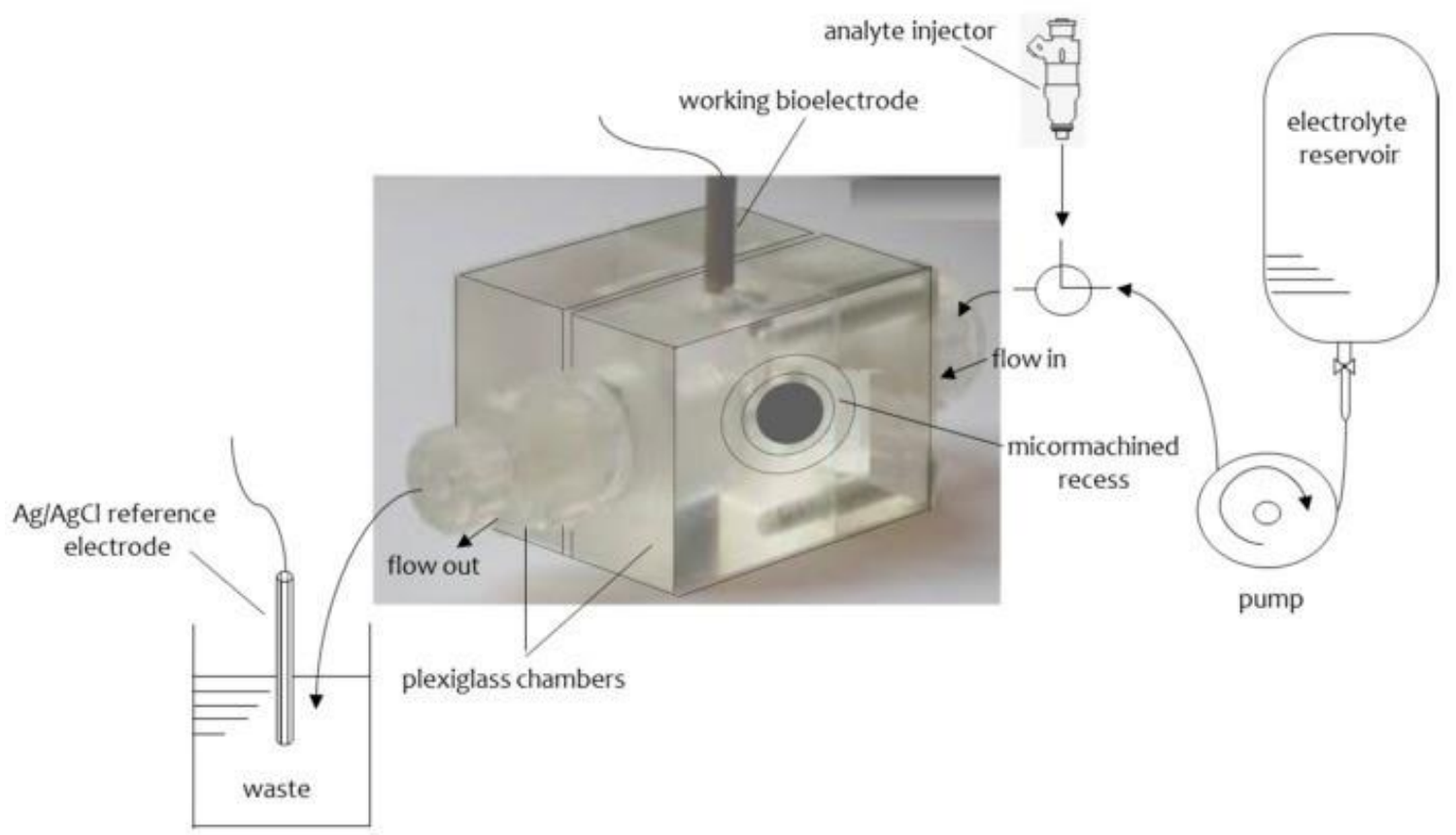

Figure 2: A diagram of the set-up for the formation of lipid membranes that were stable in electrolyte solution [from ref. 11].

\section{Polymer-supported bilayer lipid membranes}

The use of a polymer-supported lipid film has been used to stabilize lipid membrane-based devices in the air for periods of over one month [18].

These stabilized lipid films in air have also been used for the rapid detection of atrazine and for the selective and sensitive (nM detection limits) of simazine, areazine and propoazine. The preparation of stabilized in air lipid membranes was reported by Nikolelis group. The lipids used were previously described. No receptor was used in these detections. The polymer stable in air lipid membranes were constructed as previously has been described $[19,20]$ and is as follows: $0.07 \mathrm{~mL}$ of methacrylic acid, $0.8 \mathrm{~mL}$ of ethylene glycol dimethacrylate, $8 \mathrm{mg}$ of 2,2'azobis-(2-methylpropionitrile) and $1.0 \mathrm{~mL}$ of acetonitrile are added in $0.8 \mathrm{~mL}$ of a suspension that contained $4 \% \mathrm{w} / \mathrm{v}$ DPPC in a solvent of $\mathrm{n}$ hexane [which evaporates and the lipid membranes are "solvent-free"). Then nitrogen is allowed to pass through this mixture and a sonication follows. A volume ot $0.15 \mathrm{~mL}$ of this suspension is placed on the microfilter (Whatman, UK, GF/F microfiber glass disk haning diameter of $0.9 \mathrm{~cm}$ and pore size of 0.7 $\mu \mathrm{m})$ and the filters are irradiated with a UV deuterium lamp. The experimental instrumentation was the same as in Fig. 1. These films were stabilized and could be stored $\ln$ air for at least 1 month.

\section{Polymeric lipid membranes supported on graphene microelectrodes}

Our group has prepared an electrode that was composed from a lipid film on a copper wire that contained graphene nanosheets [21-23]. The high electrical conductivity of graphene is due to zero-overlap semimetal with electron and holes as charge carriers. Each carbon atoms have six electrons, and the four outermost electrons are available for chemical bonding, but in the 2-D plane, each atom is connected to three other carbon atoms, and one electron is 
freely available for electronic conduction in the 3 -D space. These free electrons present above and below the graphene sheet are called pi $(\pi)$ electrons and enhance the carbon-to-carbon bonds. These bonding and antibonding of these $\pi$-orbitals dictate the electronic properties at low energies. The relatively high electrical and thermal conductivity of copper is often the main reason for selecting copper for the myriad of electrical and electronic applications in use today. The electrical conductivity scale established in 1913 was based on a pure copper standard defined as $100 \%$. These nanobiosensors were utilized for the fast monitoring of food and environmental toxicants [21-23] such as urea using the enzyme urease, cholesterol (using cholesterol oxidease), cholera toxin (using its receptor) and saxitoxin (using its receptor). The lipid used in these detections was phosphatidylcholine.

The construction of graphene microelectrodes has been reported in the literature [21-23]. $\mathrm{N}$ methyl-pyrrolidone (NMP) was mildly sonicated for 180 hours and centrifuged at 700 $\mathrm{rpm}$ for $2 \mathrm{~h}$ which provides a homogeneous dispersion $(\sim 0.4 \mathrm{mg} / \mathrm{mL})$. This dispersion was poured onto a copper wire $(0.25 \mathrm{~mm}$ in diameter) which was placed on a glass microfiber filter and the solvent was evaporated. The copper acted as the connection for the electrochemical experiments.

The method of the construction of the lipid film nanobiosensors was reported in the literature [21-23]. The "receptor" molecules were inserted in these devices prior to polymerization by injecting $15 \mu \mathrm{L}$ of the "receptor" suspension on the polymerization mixture. The filtersupported polymeric BLMs were finally mounted onto the copper wire that contained the graphene nanosheets.

\section{Polymer lipid films supported on $\mathrm{ZnO}$ microelectrodes}

Potentiometric biosensors based on $\mathrm{ZnO}$ nanowalls and nanowires with stabilized polymer lipid films

The unmodified $\mathrm{ZnO}$ nanowalls electrodes on an aluminum ( $\mathrm{Al}$ ) foil can be prepared by the well known sonochemical technique of Nayak et al. [24]. The $\mathrm{ZnO}$ nanowires were constructed following the method as previously reported $[25,26]$. The construction of the stable lipid membranes for the detection of cholesterol was reported in the literature by Nikolelis group [27] and the technique was similar to the graphene microelectrode as previously described but instead of graphene, we used $\mathrm{ZnO}$ nanowalls electrodes. These devices were used for the detection of cholesterol (using the enzyme cholesterol oxidase) and uric acide (using urecase). The lipid used in these detections were DPPC and DPPA.

The enzyme (uricase) was incorporated in $\mathrm{ZnO}$ nanowires with deposited lipid films prior to polymerization as reported [28]. Construction of the uricase microelectrode was finalized by encapsulation of the filter-supported polymer lipid membrane onto copper wire containing the $\mathrm{ZnO}$ nanowires.

\section{Applications of lipid film nanobiosensors}

The advantages of lipid membrane devices are many: these films are biocompatible, they have fast response times on the order of seconds, high sensitivity (on the order of $\mathrm{nM}$ detection limits) and selectivity and are small size. The new generation of stabilized lipid film nanobiosensors has the potentiality to prepare analytical devices that are portable with high stability in air ans eventually can be commercialized following an exaluation/ validation...It is also expected to be used in "difficult" detections such as analysis of allergens or antibiotics in fish, etc. 


\section{Nanotechnological advances of Lipid film-based biosensors for the rapid detection of biological compounds and toxicants}

DOI: https://doi.org/10.36811/jca.2019.110004

An atrazine lipid membrane device biosensor was described in the literature; this biosensor was based on microfiber glass filters between two Saran-Wrao ${ }^{\mathrm{TM}}$ partition in which the lipid was immobilized [29]. A transient ion current signal was obtained within $1 \mathrm{~min}$ following the injection of the herbicide into the electrolyte. The introducing an anionic lipid (35\% DPPA) in the lipid films and calcium ions in the electrolyte solution increased the sensitivity of the method.

A flow injection analysis of mixtures of simazine, atrazine and propazine when using mixtures of phosphatidylcholine and dipalmitoylphosphatidic acid in glass fiber filter-supported lipid membranes was described in the literature [30]. When a sample that contained mixtures of these compounds was injected into a flowing $0.1 \mathrm{M} \mathrm{KCl}$ solution, a transient ion current signal was obtained in less than 2 minutes following the injection. The current heights of these signals were related to the herbicide concentration with micromolar detection limits. The time of appearance of the transient signal varied depending on the hydrophobicity of each compound and larger in simazine and smaller in atrazine and propazine which has permitted the simultaneous monkitoring of these triazines in mixtures.

A potentiometric urea lipid film-based device on graphene nanoelectrodes has been reported [31]. A simplified version of this nanobiosensor is shown in Figure 3. The main characteristics of this biosensor are excellent reproducibility, sensitivity, selectivity, reusability, and fast response times within the concentration range of urea between $1 \times 10^{-6} \mathrm{M}$ to $1 \times 10^{-3} \mathrm{M}$.

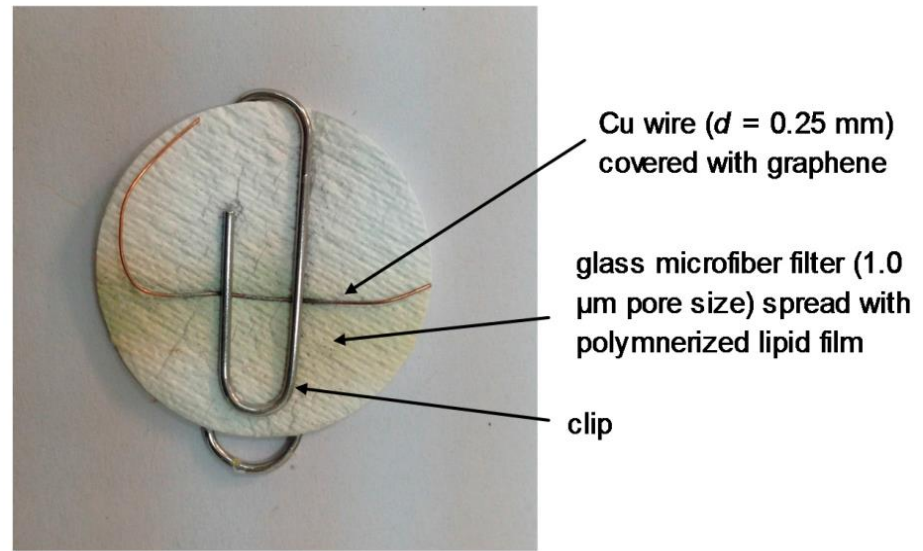

Figure 3: Picture of the lipid film device on graphene minielectrode which was used for the potentiometric detection of urea (reprinted from reference 32). The polymer that has been deposited on the GF/F filter is used to stabilize the lipid film, the copper wire is used.

The electrochemical interactions of cholera toxin with polymer lipid membranes with deposited ganglioside GM1 was described in the literature [26]. Injections of cholera toxin in the flowing streams of an electrolyte solution, provided a current signal of which the peak height was related to the concentration of the toxin in the solution (detection limits $0.06 \mu \mathrm{M}$ ). The response times and detection limits became better when a polymer lipid film on graphene nanosheets (i.e., response times of five minutes, and detection limits of $1 \mathrm{nM}$ ) was used [26]. The method was validated in lake water samples.

An electrochemical nanobiosensor for the determination of saxitoxin was reported in the literature [23]. The nanosensor was based on graphene nanosheets with stabilized lipid membranes and immobilized anti-STX. An excellent selectivity, sensitivity and detection limits $(1 \mathrm{nM})$ for the determination of saxitoxin with rapid response times (ie., 5-20 minutes) and were obtained.

A potentiometric cholesterol nanosesor was reported by immobilizing cholesterol oxidase in polymer lipid films on $\mathrm{ZnO}$ nanowalls [27]. The 
enzyme was codeposited into the lipid membrane prior polymerization on the $\mathrm{ZnO}$ nanowalls surface and provided a sensitive, selective, stable and reproducible cholesterol device. The present biosensor has shown biocompatibility and could be implanted in the human body.

An electrochemical nanosensor for uric acid has been described by immobilizing uricase in polymer lipid film on $\mathrm{Zn}$ nanowires [28]. This device has shown high sensitivity selectivity, stability and reproducibility. The presence of a cationic lipid in the lipid films has increased the sensitivity of the method by two-fold.

\section{Conclusions}

The present review describes nanobiosensors that are based on lipid membranes forr the fast detection and monitoring of biological compounds and toxicants such as herbicides, toxins, urea, cholesterol, etc and provides the advantages of lipid membrane devices (i.e. high sensitivity and selectivity, fast response times, portability, etc). It is of common sense that advances in nanotechnology will further provide biosensors with even improved characteristics.

Regardless the scope of research, lipid membrane platforms have become indispensable tools in biosensing and cell studies. Many challenges lie ahead, mostly referring to the minimization of matrix effects, membrane reproducibility and sensor reliability [11].

The results have shown that these lipid filmbased devices can be stored and used after remaining in the air for periods of one month and can be easily constructed at low cost. The response times of these nanosensors are on the order of seconds and are not bulky and much cheaper than chromatographic units; these detectors can be complimentary to LC and gas chromatographic instruments for in-field applications for the rapid detection of food and environmental toxicants and in clinical analysis. These toxicants include toxins, carbamates, hydrazines, hormones, polycyclic aromatic hydrocarbons, glucose, cholesterol etc with high sensitivity and selectivity, rapid response times, portability, etc.

\section{References}

1. Pandit S, Dasgupta D, Dewan N, et al. 2009. Nanotechnological advances in biosensors. Sensors. 9: 8907-8910.

2. Suravi Pandit, Debaprotim Dasgupta, Nazneen Dewan, et al. 2016. Nanotechnology based biosensors and its application. Pharma Innovation Journal. 5: 18-25. Ref.: https://bit.ly/342j8Dc

3. Gould SB. 2018. Membranes and evolution. Current Biology. 28: 381-385. Ref.: https://bit.ly/37g24Ma

4. Ebert A, Hannesschlaeger C, Goss K.-U, et al. 2018. Passive permeability of planar lipid bilayers to organic anions. Biophysical Journal. 115: 1931-1941. Ref.: https://bit.ly/2pAc8Pa

5. Vacek J, Zatloukalova M, Novak D. 2018. Electrochemistry of membrane proteins and protein-lipid assemblies. Current Opinion Electrochemistry. 12: 73-80. Ref.: https://bit.ly/2qqSMwi

6. Nikoleli GP, Nikolelis DP, Evtugyn G, et al. 2016. Advances in lipid film-based biosensors. TrAC Trends in Analytical Chemistry. 79: 210-221. Ref.: https://bit.ly/331mTHT

7. Mazur F, Bally M, Städler B, et al. 2017. Liposomes and lipid bilayers in biosensors. Advances in Colloid and Interface Science. 249: 88-99. Ref.: https://bit.ly/2XtrxgH

8. Raghunathan K, Kenworthy AK. 2018. Dynamic pattern generation in cell membranes: Current insights into membrane organization, BBA Biomembranes. 1860: 2018-203. Ref.: https://bit.ly/2rXSeOV

9. Kalyankar ND, Sharma MK, Vaidya SV, et al. 2006. Arraying of intact liposomes into chemically functionalized microwells. 
Langmuir. 22: 5403-5411. Ref.: https://bit.ly/2qqE0ph

10. Siontorou CG, Nikoleli GP, Nikolelis DP, et al. 2017. Artificial lipid membranes: past, present, and future. Membranes. 7: 38-61. Ref.: https://bit.ly/2XqDvHK

11. Nikoleli GP, Nikolelis DP, Siontorou CG, et al. 2018. Lipid membrane nanosensors for environmental monitoring: the art, the opportunities, and the challenges, Sensors. 18: 284-298. Ref.: https://bit.ly/2KwpQd2

12. Pandit S, Dasgupta D, Dewan N, et al. 2016. Nanotechnology based biosensors and its application. Pharma Innovation Journal. 5: 18-25. Ref.: https://bit.ly/2KwqkQo

13. Nikoleli GP, Siontorou CG, Nikolelis MT, et al. 2019. Recent lipid membranebased biosensing platforms. Applied Sciences (Switzerland). 9: 1745-1764. Ref.: https://bit.ly/2r2jPy2

14. Aljerf L, AlHamwi. 2018. Carbon nanotubes - synthesis developmental engineering demands will overcome the health challenge of nanotoxicity and its acute mortality for humans. Madridge Journal of Nanotechnology \& Nanoscience. 3: 116-118. Ref.: https://bit.ly/2KAoSg5

15. Nikoleli GP, Nikolelis DP, Siontorou CG, et al. 2018. The Application of Lipid Membranes in Biosensing. Membranes. 8: 108-123. Ref.: https://bit.ly/2QyD9gS

16. Andreou VG, Nikolelis DP. 1998. Flow injection monitoring of aflatoxin $\mathrm{M}_{1}$ in milk and milk preparations using filtersupported bilayer lipid membranes. Anal. Chem. 70: 2366-2371. Ref.: https://bit.ly/33YTDmk

17. Nikolelis DP, Siontorou CG, Andreou VG, et al. 1995. Stabilized bilayer-lipid membranes for flow-through experiments. Electroanalysis. 7: 531-536. Ref.: https://bit.ly/2QxvO1i

18. Nikolelis DP, Mitrokotsa M. 2002. Stabilized lipid film-based biosensor for atenolol. Biosensors and Bioelectronics. 17: 565-572. Ref.: https://bit.ly/2qqHKaj
19. Nikolelis DP, Raftopoulou G, Nikoleli GP, et al. 2006. Stabilized lipid membrane based biosensors with incorporated enzyme for repetitive uses. Electroanalysis. 18: 2467-2474. Ref.: https://bit.ly/2Qswsgq

20. Nikolelis DP, Raftopoulou G, Chatzigeorgiou P, et al. 2008. Optical portable biosensors based on stabilized lipid membrane for the rapid detection of doping materials in human urine. Sens. Actuators B Chem. 130: 577-582. Ref.: https://bit.ly/331svlx

21. Bratakou S, Nikoleli GP, Siontorou CG, et al. 2016. Electrochemical biosensor for naphthalene acetic acid in fruits and vegetables based on lipid films with incorporated auxin-binding protein receptor using graphene electrodes. Electroanalysis. 28: 21712177. Ref.: https://bit.ly/2CT4Glg

22. Karapetis S, Nikoleli GP, Siontorou CG, et al. 2016. Development of an electrochemical biosensor for the rapid detection of cholera toxin based on air stable lipid films with incorporated ganglioside GM1 using graphene electrodes. Electroanalysis. 28: 15841590. Ref.: https://bit.ly/37jqynP

23. Bratakou S, Nikoleli GP, Siontorou GC, et al. 2017. Development of an electrochemical biosensor for the rapid detection of saxitoxin based on air stable lipid films with incorporated Anti-STX using graphene electrodes. Electroanalysis. 29: 990-997. Ref.: https://bit.ly/2QwBhFr

24. Naval AP, Katzenmeyer AM, Gosho Y, et al. 2012. Sonochemical approach for rapid growth of zinc oxide nanowalls. Applied Physics A. 107: 661-667. Ref.: https://bit.ly/2Oo1148

25. Usman Ali SM, Alvi NH, Ibupoto Z, et al. 2011. Selective potentiometric determination of uric acid with uricase immobilized on $\mathrm{ZnO}$ nanowires, Sens. Actuators B. 152: 241-247. Ref.: https://bit.ly/2KwuAiQ 
26. Vaface M, Youzbashizade H. 2007. Production of zinc oxide nanoparticles by liquid phase processing: an investigation on optical properties. Materials Science Forum. 553: 252-256. Ref.: https://bit.ly/35cWpEO

27. Psychoyios VN, Nikoleli GP, Tzamtzis N, et al. 2013. Potentiometric cholesterol biosensor based on $\mathrm{ZnO}$ nanowalls and stabilized polymerized lipid film, Electroanalysis. 25: 367-372. Ref.: https://bit.ly/2QAt1En

28. Tzamtzis N, Psychoyios VN, Nikoleli GP, et al. 2012. Flow Potentiometric Injection Analysis of Uric Acid Using Lipid Stabilized Films with Incorporated Uricase on $\mathrm{ZnO}$ Nanowires. Electroanalysis. 24: 1719-1725. Ref.: https://bit.ly/2CX73Dv

29. Nikolelis DP, Andreou VG. 2005. Electrochemical transduction of interactions of atrazine with bilayer lipid membranes. Electroanalysis. 8: 643-647. Ref.: https://bit.ly/2rSZ5sM

30. Nikolelis DP, Siontorou CG. 1996. Flow injection monitoring and analysis of mixtures of simazine, atrazine, and propazine using filter-supported bilayer lipid membranes (BLMs). Electroanalysis. 8: 907-912. Ref.: https://bit.ly/37ilL66

31. Nikoleli GP, Israr MQ, Tzamtzis N, et al. 2012. Structural characterization of graphene nanosheets for miniaturization of potentiometric urea lipid film-based biosensors. Electroanalysis. 24: 12851295. Ref.: https://bit.ly/37jzPw3

32. Nikoleli GP, Siontorou CG, Nikolelis DP, et al. 2017. Biosensors based on lipid modified graphene microelectrodes. Carbon. 3: 9. Ref.: https://bit.ly/35k37ch

33. Nikoleli GP, Nikolelis DP, Tzamtzis N. 2011. Development of an electrochemical biosensor for the rapid detection of cholera toxin using air stable lipid films with incorporated ganglioside GM1. Electroanalysis. 23: 2182-2189. Ref.: https://bit.ly/2CYUiIO 